\title{
Fetal heart rate signal dataset for training morphological analysis methods and evaluating them against an expert consensus.
}

\author{
S.Boudet, A. Houzé l'Aulnoit, R. Demailly, A. Delgranche, L. Peyrodie, R. Beuscart, D. Houzé de \\ l'Aulnoit
}

\begin{abstract}
The fetal heart rate (FHR) is a screening signal for preventing fetal hypoxia during labor. When experts analyze this signal, they have to position a baseline and identify decelerations and accelerations. These steps can potentially be automated and made more objective by data processing analysis, but training and evaluation datasets are required. Here, we describe a dataset of 155 FHR recordings in which a reference baseline, accelerations and decelerations have been annotated by expert consensus. 66 FHR recordings with a shared expert analysis have been included in a training dataset, and 90 other FHR recordings with a non-shared expert analysis have been included in an evaluation dataset. Researchers wishing to evaluate their automatic analysis method should submit their results for comparison with the expert consensus. The dataset also contains the results produced by 11 re-coded automatic analysis methods from the literature. All the data are available at http://utsb.univcatholille.fr/fhr-review.
\end{abstract}

Index Terms - fetal heart rate, baseline, acceleration, deceleration, dataset

\section{INTRODUCTION}

$\mathrm{V}$ ISUAL FHR analyses are subject to high inter- and intra-expert variability, particularly during labor. In order to provide a more objective analysis, automatic analysis methods (AAMs) have been developed with a view to reproducing an expert analysis. This consists in drawing a baseline and determining the beginning and end of each acceleration and deceleration (A/D). Here, we present a first dataset that can be used to train AAMs and a second dataset that can evaluate them against an expert consensus. The only other public dataset of FHR signal on literature is the CTU-UHB Intrapartum Cardiotocography Database [4] but the signals are not analyzed.

All the data and source codes are available at http://utsb.univ-catholille.fr/fhr-review/.

- S.B is with Biomedical Signal Processing Unit (UTSB), Faculté de Médecine et Maïeutique, UCLille, F-59800, Lille, France

- A.H.A and R.B are with Univ Nord de France; CHU Lille; UDSL EA2694, F-59000, Lille, France

- A.H.A., R.D, A.D.. and D.H.A are with Obstetrics Department, Lille Catholic Hospital, Lille Catholic University, F-59020, Lille, France

- L.P. is with Yncréa-HEI, 59800 Lille, France.

\section{Experimental Design, Materials, AND METHODS}

The dataset is divided into two parts:

- $\quad$ a training dataset (as used in [2]) containing 66 FHR recordings

- $\quad$ an evaluation dataset (presented in [1]) containing 90 FHR recordings.

The 66 recordings in the training dataset correspond to 34 signal reconstructions from scanned paper recordings and 32 recordings captured digitally from the cardiotocograph. The mean (range) recording time is $90 \mathrm{~min}(30 \mathrm{~min}-7$ hours). These correspond to intermediate and difficult-toassess recordings.

The evaluation dataset contains 90 recordings captured digitally from the cardiotocograph. The mean (range) recording time is $105 \mathrm{~min}$ ( $90 \mathrm{~min}-120 \mathrm{~min}$ ). There are 30 easy to-assess recordings, 30 intermediate recordings, and 30 difficult-to-assess recordings.

The FHR recordings are stored as binary . fhr files. The signals were sampled at $4 \mathrm{~Hz}$ and stored in the following format. For each sample, a uint32 serves as the UNIX timestamp for the beginning of the recording. Next, a uint16 corresponds to the FHR from the first sensor (multiplied by 4), a uint16 for the FHR signal from the second sensor 
(multiplied by 4), a uint8 for the TOCO signal (multiplied by 2 ), and a uint 8 for signal quality (0: no signal, 1: low-quality signal, 2: high-quality signal). The FHR signal is set to 0 when it is missing. The .fhr files can be opened with the fhropen.m function in MATLAB.

Standard preprocessing can be applied by using the fhrpreprocess.m function in MATLAB. This consists in merging FHR1 and FHR2, removing aberrant samples, and generating a linear interpolation of any missing parts.

Expert analyses are stored as expertAnalyses.mat MATLAB files. Each file contains a table called "data". Each element of this table corresponds to a recording on which information are stored, as follows:

- filename: the name of the file.

- baseline: the baseline signal, sampled at $4 \mathrm{~Hz}$.

- accelerations: a 2 x $n$ table that stores the beginning and end of each acceleration (in minutes).

- decelerations: the same information for decelerations.

- overshoots: the same information for overshoots (Are excluded from evaluation; see [1])

- unreliableSignal: periods of maternal heart rate or too much missing signal preventing good analysis (excluded from evaluation)
- notToAnalyse: periods not to be analyzed due to insufficient signal before or after for baseline positioning

- trainingData: a Boolean set to 1 if the recording is part of the training dataset and 0 if it is part of the evaluation dataset.

The baseline, accelerations, decelerations, and overshoots are not publicly shared for the recordings in the evaluation dataset to avoid any training on those data.

The expert analysis corresponds to a consensus by four experts. They first chose the points for their estimated baseline on a screen and a program drew the baseline by linear interpolation. Next, the experts set the beginning/end of each five types of periods (accelerations, decelerations, overshoots, unreliable signals, and signal not to be analyzed). A more rigorous consensus methodology has been applied to the evaluation dataset (as described in [1]), in order to ensure the best possible data quality. Figure 1 shows an example of an expert analysis.

The dataset contains also analyses of 11 re-coded AAMs, which are stored in . mat files. These files have the same format as the expert analyses, except that they only contain the filename, baseline, acceleration and deceleration variables.

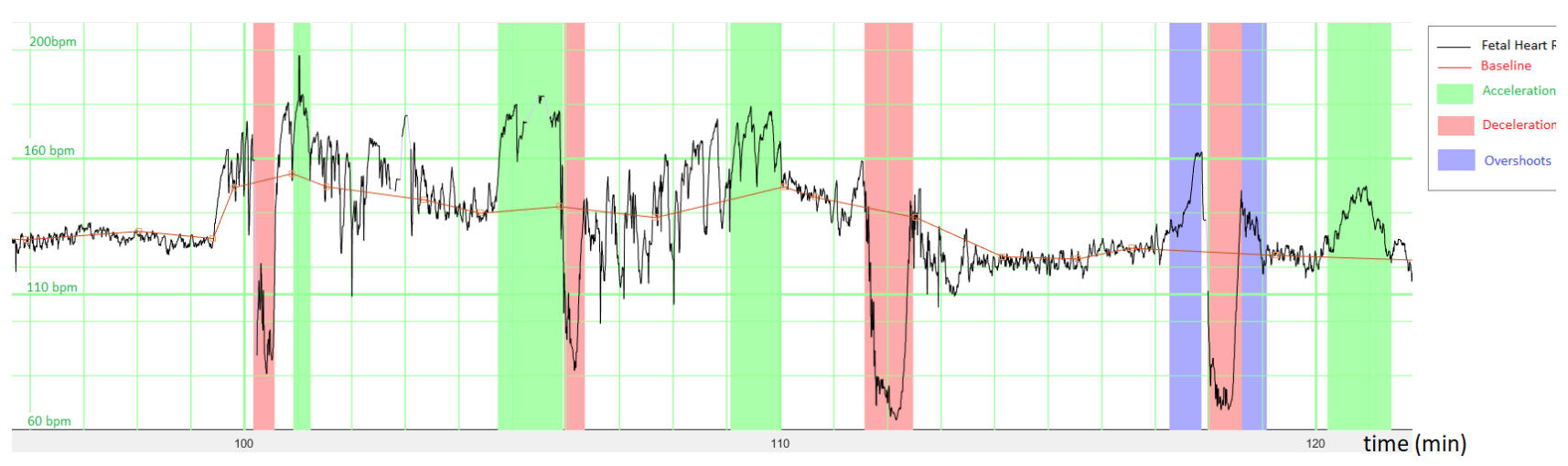

FIG. 1. AN EXAMPLE OF AN EXPERT ANALYSIS OF AN FHR SIGNAL FROM THE TRAINING DATASET.

TABLE 1

THE FILES FOR THE 11 AUTOMATED ANALYSIS METHODS

\begin{tabular}{|c|c|c|c|c|}
\hline Filename(s) & A_std.mat & C_orig.mat/ C_std.mat & H_std.mat & J_orig.mat / J_std.mat \\
\hline Method & $\begin{array}{c}\text { Ayres de Campos et } \\
\text { al. (2000) [6] }\end{array}$ & Cazares et al. (2002) [7] & Houzé et al. (1990) [8] & Jimenez et al. (2002) [9] \\
\hline
\end{tabular}

\begin{tabular}{|c|c|c|c|c|}
\hline Filename(s) & L_std.mat & MD_std.mat & $\begin{array}{c}\text { MT_orig.mat / } \\
\text { MT_std.mat }\end{array}$ & MG_std.mat \\
\hline Method & Lu et Wei (2012) [10] & Maeda et al. (2012) [11] & $\begin{array}{c}\text { Mantel et al. (1990) } \\
{[12,13]}\end{array}$ & $\begin{array}{c}\text { Mongelli et al. (1997) } \\
{[14]}\end{array}$ \\
\hline
\end{tabular}

\begin{tabular}{|c|c|c|c|}
\hline Filename(s) & P_std.mat & T_orig.mat / T_std.mat & W_std.mat \\
\hline Method & $\begin{array}{c}\text { Pardey et al. (2002) } \\
{[15]}\end{array}$ & Taylor et al. (2000) [16] & $\begin{array}{c}\text { Wróbel et al. (2013) } \\
{[17]}\end{array}$ \\
\hline
\end{tabular}


Table 1 gives the file names for the analyses of each of the 11 AAMs. Although each AAM provides a specific baseline, only some provide an algorithm for A/D detection (corresponding to *_orig.mat files). A standard method for A/D detection [1] has also been applied to all baseline methods (corresponding to * std.mat files).

Researchers wishing to evaluate their AAM should submit their analysis in the same format (baseline and A/D, although A/D are not compulsory). The results of the evaluation will be published at http://utsb.univ-catholille.fr/fhr-review/.

A toolbox containing the MATLAB code for the 11 AAMs, an FHR viewer, the evaluation procedure, and some standard tools for preprocessing FHR data is also available at http://utsb.univ-catholille.fr/fhr-review [3]. Another public FHR analysis software called CTG-OAS [5] could be used on this dataset but the files must first be converted in their format.

\section{COMPLIANCE WITH ETHICAL STANDARDS}

\section{Funding:}

This research did not receive any specific grant from funding agencies in the public, commercial, or not-for-profit sectors.

\section{Conflict of Interest:}

All authors declare that they have no conflict of interest.

\section{Ethical approval:}

All procedures involving human participants were performed in accordance with the ethical standards of the institutional and/or national review boards and with the 1964 Declaration of Helsinki and its later amendments or comparable ethical standards.

This research complied with generally accepted scientific principles and medical research ethical standards and was approved by the local independent ethics committee (CIER; Lille Catholic Hospitals; filing number 2016-08-06). The databases were registered with the French National Data Protection Commission.

\section{Informed consent:}

All study participants provided their informed consent.

\section{REFERENCES}

[1] A. Houzé de l'Aulnoit, S. Boudet, R. Demailly, A. Delgranche, M. Génin, L. Peyrodie, R. Beuscart, D. Houzé de l'Aulnoit, Automated fetal heart rate analysis for baseline determination and acceleration/deceleration detection: A comparison of 11 methods versus expert consensus, Biomed. Signal Process. Control. 49 (2019) 113-123.

[2] A.H. de l'Aulnoit, S. Boudet, R. Demailly, L. Peyrodie, R. Beuscart, D.H del'Aulnoit, Baseline fetal heart rate analysis: Eleven automatic methods versus expert consensus, in: IEEE, 2016: pp. 3576-3581. doi:10.1109/EMBC.2016.7591501.
[3] Boudet, A. Houzé de l'Aulnoit, R. Demailly, A. Delgranche, L. Peyrodie, R. Beuscart, D. Houzé de l'Aulnoit, A Fetal Heart Rate Morphological Analysis Toolbox for MATLAB, Preprints 2019, doi: 10.20944/preprints201906.0139.v1.

[4] V. Chudáček, J. Spilka, M. Burša, P. Janků, L. Hruban, M. Huptych, L. Lhotská, Open access intrapartum CTG database, BMC Pregnancy Childbirth. 14 (2014). doi:10.1186/1471-2393-14-16.

[5] Z. Cömert, A.F. Kocamaz, Open-access software for analysis of fetal heart rate signals, Biomed. Signal Process. Control. 45 (2018) 98-108. doi:10.1016/j.bspc.2018.05.016.

[6] D. Ayres-de Campos, J. Bernardes, A. Garrido, J. Marques-de-Sá, L. Pereira-Leite, SisPorto 2.0: a program for automated analysis of cardiotocograms, J. Matern. Fetal Med. 9 (2000) 311-318. doi:10.1002/15206661(200009/10)9:5<311::AID-MFM12>3.0.CO;2-9.

[7] S.M. Cazares, Automated identification of abnormal patterns in the intrapartum cardiotocogram, University of Oxford, 2002.

[8] D. Houzé de l'Aulnoit, R. Beuscart, G. Brabant, L. Corette, M. Delcroix, Real-time analysis of the fetal heart rate, in: IEEE, 1990: pp. 1994-1995. doi:10.1109/IEMBS.1990.692125.

[9] L. Jimenez, R. Gonzalez, M. Gaitan, S. Carrasco, C. Vargas, Computerized algorithm for baseline estimation of fetal heart rate, in: IEEE, 2002: pp. 477-480. doi:10.1109/CIC.2002.1166813.

[10] Y. Lu, S. Wei, Nonlinear baseline estimation of FHR signal using empirical mode decomposition, in: IEEE, 2012: pp. 1645-1649. doi:10.1109/ICoSP.2012.6491896.

[11] K. Maeda, M. Utsu, Y. Noguchi, F. Matsumoto, T. Nagasawa, Central Computerized Automatic Fetal Heart Rate Diagnosis with a Rapid and Direct Alarm System, Open Med. Devices J. 4 (2012) 28-33. doi:10.2174/1875181401204010028.

[12] R. Mantel, H.P. van Geijn, F.J. Caron, J.M. Swartjes, E.E. van Woerden, H.W. Jongsma, Computer analysis of antepartum fetal heart rate: 1. Baseline determination, Int. J. Biomed. Comput. 25 (1990) 261-272. doi:https://doi.org/10.1016/0020-7101(90)90030-X.

[13] R. Mantel, H.P. van Geijn, F.J. Caron, J.M. Swartjes, E.E. van Woerden, H.W. Jongsma, Computer analysis of antepartum fetal heart rate: 2 . Detection of accelerations and decelerations, Int. J. Biomed. Comput. 25 (1990) 273-286. doi:https://doi.org/10.1016/0020-7101(90)90031-O.

[14] M. Mongelli, R. Dawkins, T. Chung, D. Sahota, J.A. Spencer, A.M. Chang, Computerised estimation of the baseline fetal heart rate in labour: the low frequency line, Br. J. Obstet. Gynaecol. 104 (1997) 1128-1133. doi:https://doi.org/10.1111/j.1471-0528.1997.tb10935.x.

[15] J. Pardey, M. Moulden, C.W.G. Redman, A computer system for the numerical analysis of nonstress tests, Am. J. Obstet. Gynecol. 186 (2002) 1095-1103. doi:https://doi.org/10.1067/mob.2002.122447.

[16] G.M. Taylor, G.J. Mires, E.W. Abel, S. Tsantis, T. Farrell, P.F. Chien, Y. Liu, The development and validation of an algorithm for real-time computerised fetal heart rate monitoring in labour, BJOG Int. J. Obstet. Gynaecol. 107 (2000) 1130-1137. doi:https://doi.org/10.1111/j.14710528.2000.tb11112.x.

[17] J. Wróbel, K. Horoba, T. Pander, J. Jeżewski, R. Czabański, Improving fetal heart rate signal interpretation by application of myriad filtering, Biocybern. Biomed. Eng. $33 \quad$ (2013) 211-221. doi:10.1016/j.bbe.2013.09.004.Ayres-de-Campos, C.Y. Spong, E. Chandraharan, FIGO consensus guidelines on intrapartum fetal monitoring: Cardiotocography, Int. J. Gynecol. Obstet. 131 (2015) 13-24. 


\section{ANNEXE}

\section{Specifications Table}

\begin{tabular}{|c|c|}
\hline Subject area & Biomedical signal processing \\
\hline More specific subject area & Automatic analysis of the fetal heart rate (FHR) \\
\hline Type of data & Fetal heart rate recordings, annotated by expert consensus \\
\hline How data was acquired & $\begin{array}{l}\text { Signals are recorded with a cardiotocograph during labor. The signals have been } \\
\text { selected for their interest in analysis and difficulty (easy-to-assess, intermediate, } \\
\text { and difficult-to-assess recordings). } \\
\text { The recordings were annotated by expert consensus. }\end{array}$ \\
\hline Data format & $\begin{array}{l}\text { The raw signals are supplied as binary files. The expert analysis and the results for } \\
\text { the } 11 \text { automatic analysis methods are supplied as MATLAB .mat files. }\end{array}$ \\
\hline Experimental factors & $\begin{array}{l}\text { The dataset includes raw cardiotocograph signals sampled at } 4 \mathrm{~Hz} \text {, and a matlab } \\
\text { function for standard preprocessing (removal of aberrant samples and linear inter- } \\
\text { polation of missing parts). } \\
\text { The expert analysis includes the baseline signal, and the start and end of each ac- } \\
\text { celeration, deceleration and overshoot. } \\
\text { Results for the } 11 \text { automatic analysis methods (AAM) described in [1] are also pro- } \\
\text { vided. }\end{array}$ \\
\hline Experimental features & $\begin{array}{l}\text { The dataset is divided into a training dataset of } 66 \text { recordings annotated by expert } \\
\text { consensus and an evaluation dataset of } 90 \text { recordings that can be used to compare } \\
\text { methods. Researchers who wish to evaluate their methods should submit the base- } \\
\text { line and acceleration/deceleration A/D. The main evaluation criterion is the Mor- } \\
\text { phological Analysis Discordance Index (MADI) which is (described in [1]). Other } \\
\text { criteria include the baseline root mean square difference, synthetic inconsistency } \\
\text { (SI), acceleration/deceleration (A/D) sensitivity, and A/D positive predictive value. }\end{array}$ \\
\hline Data source location & Lille Catholic Hospital, Lille Catholic University, Lille, France. \\
\hline Data accessibility & $\begin{array}{l}\text { Data and source code are publicly available at http://utsb.univ-catholille.fr/fhr-re- } \\
\text { view. }\end{array}$ \\
\hline Related research article & $\begin{array}{l}\text { This paper describes the data used in [1] } \\
\text { The training dataset corresponds to the data used in [2]. } \\
\text { The toolbox used for processing the data is described in [3] }\end{array}$ \\
\hline
\end{tabular}

\section{Highlights}

- Provides a dataset for the development and training of methods for the automatic morphological analysis of FHR recordings

- Provides a benchmark for this question

- Tests 11 automatic analysis methods from the literature 